\title{
Azacytidine sensitizes acute myeloid leukemia cells to arsenic trioxide by up-regulating the arsenic transporter aquaglyceroporin 9
}

David Chau ${ }^{1 \dagger}$, Karen Ng ${ }^{1 \dagger}$, Thomas Sau-Yan Chan¹, Yuen-Yee Cheng ${ }^{1,3}$, Bonnie Fong², Sidney Tam², Yok-Lam Kwong ${ }^{1}$ and Eric Tse ${ }^{1 *}$

\begin{abstract}
Background: The therapeutic efficacy of arsenic trioxide $\left(\mathrm{As}_{2} \mathrm{O}_{3}\right)$ in acute myeloid leukemia (AML) is modest, which is partly related to its limited intracellular uptake into the leukemic cells. $\mathrm{As}_{2} \mathrm{O}_{3}$ enters cells via the transmembrane protein aquaglyceroporin 9 (AQP9). Azacytidine, a demethylating agent that is approved for the treatment of AML, has been shown to have synergistic effect with $\mathrm{As}_{2} \mathrm{O}_{3}$. We tested the hypothesis that azacytidine might up-regulate AQP9 and enhances $\mathrm{As}_{2} \mathrm{O}_{3}$-mediated cytotoxicity in AML.

Methods: Arsenic-induced cytotoxicity, the expression of AQP9, and the intracellular uptake of $\mathrm{As}_{2} \mathrm{O}_{3}$ were determined in AML cell lines and primary AML cells with or without azacytidine pre-treatment. The mechanism of AQP9 up-regulation was then investigated by examining the expression of transcription factors for AQP9 gene and the methylation status of their gene promoters.

Results: $\mathrm{As}_{2} \mathrm{O}_{3}$-induced cytotoxicity in $\mathrm{AML}$ cell lines was significantly enhanced after azacytidine pre-treatment as a result of AQP9 up-regulation, leading to increased arsenic uptake and hence intracellular concentration. Blocking AQP9-mediated $\mathrm{As}_{2} \mathrm{O}_{3}$ uptake with mercury chloride abrogated the sensitization effect of azacytidine. AQP9 promoter does not contain $\mathrm{CpG}$ islands. Instead, azacytidine pre-treatment led to increased expression of HNF1A, a transcription activator of $A Q P 9$, through demethylation of HNF1A promoter. HNF1 knockdown abrogated azacytidine-induced AQP9 up-regulation and almost completely blocked intracellular $\mathrm{As}_{2} \mathrm{O}_{3}$ entry, confirming that azacytidine enhanced $\mathrm{As}_{2} \mathrm{O}_{3}$-mediated cell death via up-regulation of HNF1A and hence increased AQP9 and $\mathrm{As}_{2} \mathrm{O}_{3}$ intracellular concentration. Azacytidine sensitization to $\mathrm{As}_{2} \mathrm{O}_{3}$ treatment was re-capitulated also in primary AML samples. Finally, azacytidine did not enhance arsenic toxicity in a liver cell line, where HNF1A was largely unmethylated.

Conclusions: Azacytidine sensitizes AML cells to $\mathrm{As}_{2} \mathrm{O}_{3}$ treatment, and our results provide proof-of-principle evidence that pharmacological up-regulation of AQP9 potentially expands the therapeutic spectrum of $\mathrm{As}_{2} \mathrm{O}_{3}$. Further clinical trial should evaluate the efficacy of azacytidine in combination with $\mathrm{As}_{2} \mathrm{O}_{3}$ in the treatment of AML.
\end{abstract}

Keywords: Acute myeloid leukemia, Arsenic trioxide, Azacytidine, Demethylating agents, Aquaglyceroporin 9

\footnotetext{
* Correspondence: ewctse@hku.hk

${ }^{\dagger}$ Equal contributors

'Division of Haematology, Department of Medicine, Queen Mary Hospital,

The University of Hong Kong, Pok Fu Lam, Hong Kong, Hong Kong

Full list of author information is available at the end of the article
} 


\section{Introduction}

Arsenic trioxide $\left(\mathrm{As}_{2} \mathrm{O}_{3}\right)$ is an important and highly efficacious drug in the management of acute promyelocytic leukemia (APL) [1,2]. It was first successfully used as a salvage therapy for relapsed APL [3]. More recently, $\mathrm{As}_{2} \mathrm{O}_{3}$ has also been shown to be effective as first line induction therapy in newly diagnosed APL $[4,5]$ and as a maintenance therapy [6]. The unique sensitivity of APL cells to $\mathrm{As}_{2} \mathrm{O}_{3}$ is likely to be related to $\mathrm{As}_{2} \mathrm{O}_{3}$-mediated degradation of the PML-RARA chimeric protein, which is an oncogenic protein produced as a result of the specific chromosomal translocation $t(15 ; 17)$ (q22;q12) $[7,8]$. In addition, $\mathrm{As}_{2} \mathrm{O}_{3}$ has also been shown to induce apoptosis through the generation of superoxides and reactive oxygen species $[9,10]$, disruption of the mitochondrial transmembrane potential with release of cytochrome $\mathrm{c}$ and caspase activation [11], and inhibition of DNA methyltransferase DNMT leading to demethylation of tumor suppressor genes [12].

Because $\mathrm{As}_{2} \mathrm{O}_{3}$ must enter cells before exerting its cytotoxic activity, the control of arsenic trafficking through the plasma membrane could conceivably modulate arsenic sensitivity. Aquaglyceroporin 9 (AQP9) is a transmembrane solute transporting protein and is expressed in human leukocytes, liver, lung, and spleen [13]. Unlike the typical aquaporin water channel, it also facilitates the passage of glycerol and many other non-charged solutes. We and others have shown that AQP9 controls the transmembrane transport of $\mathrm{As}_{2} \mathrm{O}_{3}$, thereby playing a critical role in determining the sensitivity of cells towards $\mathrm{As}_{2} \mathrm{O}_{3}$-induced cytotoxicity [14,15]. In myeloid leukemia cells, expression levels of AQP9 are directly proportional to intracellular arsenic concentrations upon $\mathrm{As}_{2} \mathrm{O}_{3}$ treatment, which translate into increased arsenic sensitivity [14]. Of the different subtypes of acute myeloid leukemia (AML), APL cells express the highest concentration of AQP9, which might in part explain their exquisite sensitivity to $\mathrm{As}_{2} \mathrm{O}_{3}$ [14]. Furthermore, all-trans retinoic acid (ATRA) up-regulates $\mathrm{AQP9}$ expression, contributing to its synergistic cytotoxic effect with $\mathrm{As}_{2} \mathrm{O}_{3}$ [14]. However, the regulation of $\mathrm{AQP9}$ expression remains unclear. Understanding the mechanisms controlling AQP9 expression may enable pharmacological strategies to be designed to up-regulate AQP9 in leukemia cells, hence constituting a potential method to expand the therapeutic spectrum of $\mathrm{As}_{2} \mathrm{O}_{3}$ in the treatment of AML.

Demethylating agents, including azacitidine and decitabine, are a standard medication for the management of myelodysplastic syndrome and elderly subjects with AML [16-19]. Recently, demethylating agents have been shown to synergize with $\mathrm{As}_{2} \mathrm{O}_{3}$ in the treatment of $\mathrm{AML}$ in vitro and in vivo [20,21]. However, the biological basis of the synergism between demethylating agents and $\mathrm{As}_{2} \mathrm{O}_{3}$ has not been defined.
In this study, we proposed that one of the mechanisms of synergism between demethylating agents and $\mathrm{As}_{2} \mathrm{O}_{3}$ might be through modulation of AQP9 expression. To test this hypothesis, we examined the effect of azacytidine treatment on AQP9 expression and plasma membrane arsenic trafficking in AML cell lines and primary AML samples.

\section{Materials and methods \\ Cells and reagents}

The human myeloid leukemia cell lines HL-60 and K562 (purchased from ATCC, Manassas, VA, USA) and the APL cell line NB4 (a kind gift from Dr. Shen ZX, Shanghai Institute of Hematology, Rui Jin Hospital, Shanghai, China) were cultured in RPMI-1640 supplemented with $10 \%$ fetal bovine serum (FBS) and $1 \%$ penicillin/streptomycin in $5 \% \mathrm{CO}_{2}$ at $37^{\circ} \mathrm{C}$. They have been characterized and tested as described previously [14]. The human leukemia line OCI-AML3 (purchased from DSMZ, Braunschweig, Germany) was cultured in $\alpha$-MEM with $20 \%$ FBS in similar conditions. The immortalized human liver cell line MIHA (a kind gift from Dr. J Roy-Chowdhury, Albert Einstein College of Medicine, New York, USA) was cultured in DMEM with 10\% FBS. MIHA has been characterized and tested as described previously [22]. Primary AML samples from peripheral blood (PB) and/or bone marrow (BM) were obtained with informed consent from patients treated at Queen Mary Hospital, Hong Kong. Primary cells were cultured in StemSpan H3000 supplemented with StemSpan CC100 cytokine cocktail (StemCell Technologies, Vancouver, Canada). Archival samples were obtained from marrow mononuclear cells of AML patients stored at $-80^{\circ} \mathrm{C}$. Procurement of these samples was approved by the institute review board according to the Declaration of Helsinki. The demethylating drug azacytidine (5-aza-2'deoxycytidine; 5'Aza) and $\mathrm{As}_{2} \mathrm{O}_{3}$ were obtained from Sigma-Aldrich (St. Louis, MO, USA). The polyclonal phycoerythrin (PE)-conjugated anti-AQP9 and $\mathrm{PE}$-conjugated isotypic control antibodies were purchased from Bioss Antibodies (Bioss Inc., Woburn, MA, USA).

\section{$\mathrm{As}_{2} \mathrm{O}_{3}$ cytotoxicity}

Cells pre-treated with or without azacytidine $(5 \mu \mathrm{M}$ for 3 days) were washed twice with phosphate-buffered saline (PBS), re-suspended in fresh RPMI-1640 supplemented with $10 \%$ FBS, and treated with various concentration of $\mathrm{As}_{2} \mathrm{O}_{3}$ (0.0, 0.3125, and $0.625 \mu \mathrm{M}$ for NB4; 0.0, 2.5, 5.0, and $10.0 \mu \mathrm{M}$ in other cells). For experiments where AQP9 blockade was involved, cells were incubated in addition with mercury chloride $\left(\mathrm{HgCl}_{2}\right)$ at $10 \mu \mathrm{M}$ for 2 hours. For 3-[4,5-dimethylthiazol-2-yl]-2,5 diphenyl tetrazolium bromide (MTT) assay, $100 \mu \mathrm{L}$ of each cell suspension was incubated for 48 hours in 96 -well plates, followed by the 
addition of MTT reagents (10 $\mu \mathrm{L}$ for 4 hours) and the solubilizing buffer (100 $\mu \mathrm{L}$ overnight), and absorbance measurement at $560 \mathrm{~nm}$. All experiments were performed in triplicates.

\section{Flow cytometric analysis}

For apoptosis assay, cells treated with or without azacytidine were analyzed for apoptotic cells using a Cytomics FC 500 flow cytometer (Beckman Coulter, Brea, CA, USA), using an annexin V: phycoerythrin and 7-AAD apoptosis detection kit (BD Biosciences, San Jose, CA, USA). Cells were incubated with respective antibodies for $15 \mathrm{~min}$ and subjected to flow cytometric analysis. At least 10,000 events were collected. All flow cytometry plots and data were acquired from at least three independent experiments.

\section{Quantification of gene expression}

Total RNA was extracted using Trizol reagent (Life technologies, Carlsbad, CA, USA), and $1 \mu \mathrm{g}$ of RNA was reversely transcribed (SuperScript III First Strand Synthesis system, Life technologies, Carlsbad, CA, USA). The resulting cDNAs were used for semi-quantitative reverse transcription polymerase chain reaction (RT-PCR) or quantitative RT-PCR (q-RT-PCR). Primers for quantification of target and control genes were designed by the Primer Express software (Applied Biosystems, Life technologies, Carlsbad, CA, USA) (primer sequences and reaction conditions were listed in Additional file 1). Quantitative RT-PCR was performed using Power SYBR Green PCR Master Mix (Applied Biosystems, Carlsbad, CA, USA) and a StepOnePlus Real Time PCR system (Applied Biosystems, Carlsbad, CA, USA). The expressions of target genes with respect to the internal control gene were analyzed with the comparative $\mathrm{C}_{\mathrm{T}}\left(\Delta \Delta \mathrm{C}_{\mathrm{T}}\right)$ method. Experiments were performed in triplicates.

\section{Western immunoblotting}

Cells were washed twice with PBS and were then lysed in RIPA buffer [RIPA: $50 \mathrm{mM}$ of Tris-HCl buffer $\mathrm{pH} 7.4$, $150 \mathrm{mM} \mathrm{NaCl}, 1 \mathrm{mM}$ EDTA, $1 \%(v / v) \mathrm{NP}-40$, and $0.25 \%$ $(w / v)$ sodium deoxycholate, with the addition of a protease inhibitor cocktail (Roche Diagnostic, Sulzfeld, Germany), $1 \mathrm{mM}$ phenylmethylsulfonyl fluoride (PMSF)]. Total protein concentration was determined using the BCA protein assay kit (Pierce Biotechnology, Rockford, IL, USA) according to the manufacturer's instructions. For Western blot analysis, antibodies against HNF1A (Cell Signaling, Danvers, MA, USA) and $\beta$-actin (Sigma, St. Louis, MO, USA) were used. For detection of bound antibodies, HRP-conjugated secondary antibodies were used (Life Technologies (Carlsbad, CA, USA)).

\section{RNA interference and transfection}

Gene knockdown experiments were performed with siRNA (sequences of siRNA in Additional file 1), with negative controls (AllStars Negative Controls, Qiagen, Venlo, Netherlands). K562 cells $\left(2 \times 10^{5}\right.$ cells in $\left.100 \mu \mathrm{L}\right)$ were transfected with siRNA (200 ng diluted in RPMI1640 medium, incubated at room temperature for 10 min with $6 \mu \mathrm{L}$ HiPerfect transfection reagent, Qiagen, Germantown, MD, USA) for $6 \mathrm{~h}$ in $5 \% \mathrm{CO}_{2}$ at $37^{\circ} \mathrm{C}$, after which $600 \mu \mathrm{L}$ of medium with FBS and antibiotics was added, followed by another $72 \mathrm{~h}$ of incubation before analysis. Experiments were performed in triplicates.

\section{Measurement of intracellular arsenic concentration}

Cells were harvested, washed twice in ice-cold PBS, pelleted, and lysed in $0.9 \mathrm{~mL}$ of double-distilled water by sonication for $10 \mathrm{~min}$. Yttrium (Chem Service, West Chester, PA, USA) dissolved in 2\% nitric acid to ten parts per billion was then added as an internal standard to the lysate, which was vortexed and centrifuged at $3000 \times g$ for $10 \mathrm{~min}$. The supernatant was collected and assayed for arsenic concentration by inductively coupled plasmamass spectrometry [23]. Experiments were performed in triplicates.

\section{Bisulfite modification of DNA, methylation-specific PCR and combined bisulfite restriction analysis}

Genomic DNA was isolated with the QIAamp DNA Blood Mini Kit (Qiagen, Germantown, MD, USA). Bisulfite modification of DNA was performed with the Zymo DNA modification kit (Zymo Research, Irvine, CA, USA). Methylation-specific PCR (MSP) specific primers for the methylated and unmethylated alleles were designed using the OLIGO 6 primer analysis software (Molecular Biology Insights, Cascade, CO, USA) (primer sequences in Additional file 1: Supplementary Information), and the PCR products were analyzed by gel electrophoresis. CpGenome universal methylated DNA (Chemicon International Inc, Billerica, MA, USA) was used as a positive control. For combined bisulfite restriction analysis (COBRA), bisulfite-modified DNA before and after treatment was amplified by PCR with primers spanning the CG-rich region of target gene promoter (primer sequences in Additional file 1: Supplementary Information) and digested with the restriction endonuclease BstUI (New England Biolabs, Ipswich, MA, USA). PCR products were analyzed by gel electrophoresis to determine the respective methylation status.

\section{Statistical analysis}

Comparative analysis of cell viability and AQP9 expression were performed by the Student's $t$-test, whereas correlation analysis on AQP9 and HNF1A expression was performed using the Pearson's $X^{2}$-test. All values were 
presented as mean \pm standard deviation (SD). Differences were considered statistically significant when $p$ value was $<0.05$.

\section{Results}

Azacytidine sensitized leukemia cells to $\mathrm{As}_{2} \mathrm{O}_{3}$-induced cytotoxicity

Of the four leukemia cell lines tested, NB4 showed the highest sensitivity to $\mathrm{As}_{2} \mathrm{O}_{3}$, whereas HL-60, K562, and OCI-AML3 had comparable sensitivities. Pre-treatment with azacytidine significantly sensitized these cells to $\mathrm{As}_{2} \mathrm{O}_{3}$-induced cytotoxicity (Figure 1A). Similar results were obtained with the annexin V/7-AAD apoptosis assay (Figure 1B,C).

\section{Azacytidine increased AQP9 level and enhanced intracellular entry of $\mathrm{As}_{2} \mathrm{O}_{3}$}

RT-PCR showed that azacytidine treatment significantly increased $A Q P 9$ gene expression (Figure 2A, upper panel). Quantitative RT-PCR confirmed a four- to fivefold increase in AQP9 mRNA upon azacytidine treatment (Figure 2A, lower panel). Flow cytometric analysis showed a corresponding increase in surface expression of AQP9 (Figure 2B). The azacytidine-induced increase in AQP9 expression was functional, as it resulted in enhanced arsenic entry into cells (Figure 2C). To verify that AQP9 actually mediated increased arsenic entry into cells, which then led to cytotoxicity, the effect of AQP9 blockade with $\mathrm{HgCl}_{2}$ was examined [24]. As shown in Figure 2D (left

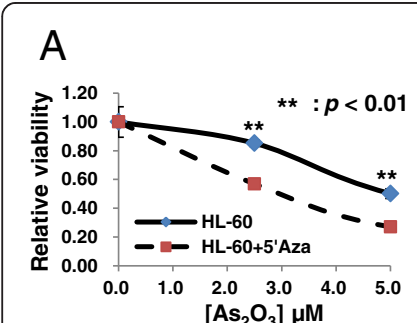

B
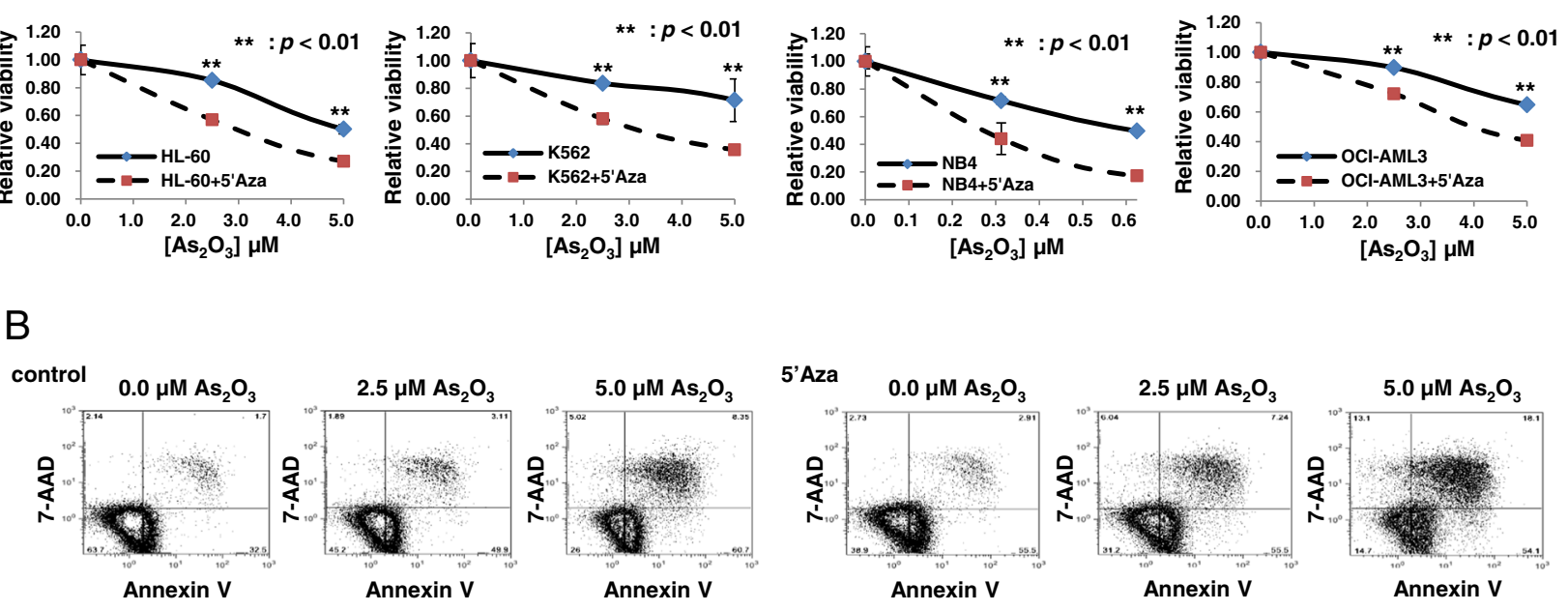

C

$$
\star *: p<0.01
$$

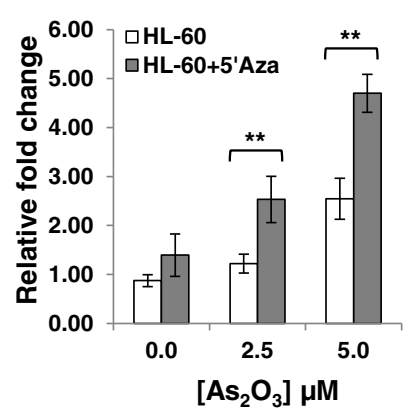

$\star \star: p<0.01$

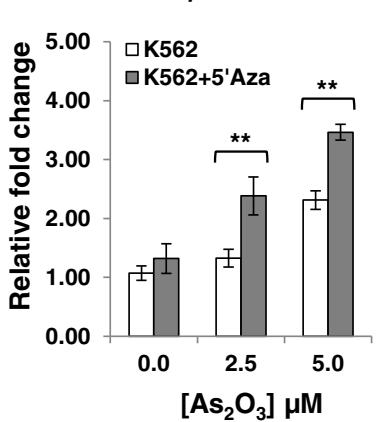

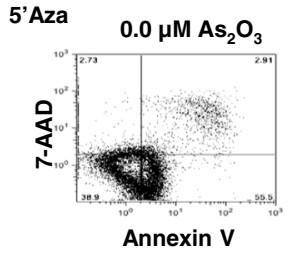
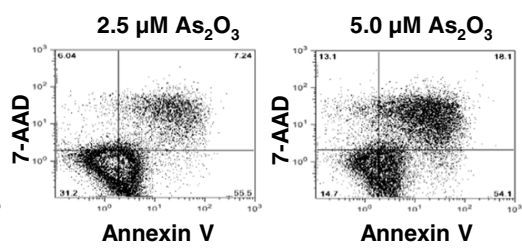

Annexin V
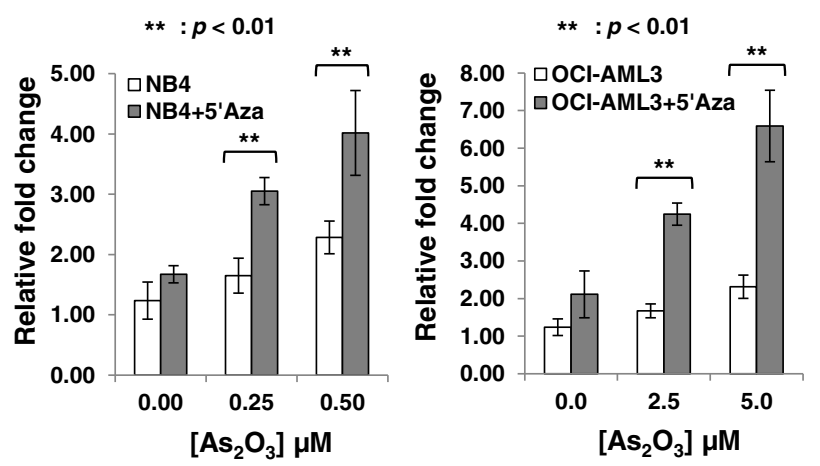

Figure 1 Sensitization of leukemia cells to $\mathrm{As}_{2} \mathrm{O}_{3}$-induced cytotoxicity with azacytidine (5'Aza) pre-treatment. (A) Dose-dependent cytotoxicity of $\mathrm{As}_{2} \mathrm{O}_{3}$ with or without 5'Aza treatment in the human AML cell lines, HL-60, K562, NB4, and OCI-AML3. As determined by MTT assay, all four cell lines pre-treated with 5'Aza exhibited significant decrease in cell viability as compared with their untreated controls. Data were acquired from three independent experiments, and relative survival of each individual cell line was normalized to its respective control. (B) Representative plot of flow cytometric analysis, showing a significant increase in $\mathrm{As}_{2} \mathrm{O}_{3}$-mediated cytotoxicity (annexin V-positive cells) in $\mathrm{K} 562$ cells pre-treatment with 5'Aza, as compared with control cells not treated with 5'Aza. (C) Bar charts showing the fold changes of $\mathrm{As}_{2} \mathrm{O}_{3}$-induced cell death (annexin V-positive cells) in each AML lines with or without 5'Aza pre-treatment. Quantitative analysis by flow cytometry further confirmed a significant increase in $\mathrm{As}_{2} \mathrm{O}_{3}$-induced apoptotic cell death after $5^{\prime}$ Aza pre-treatment. 


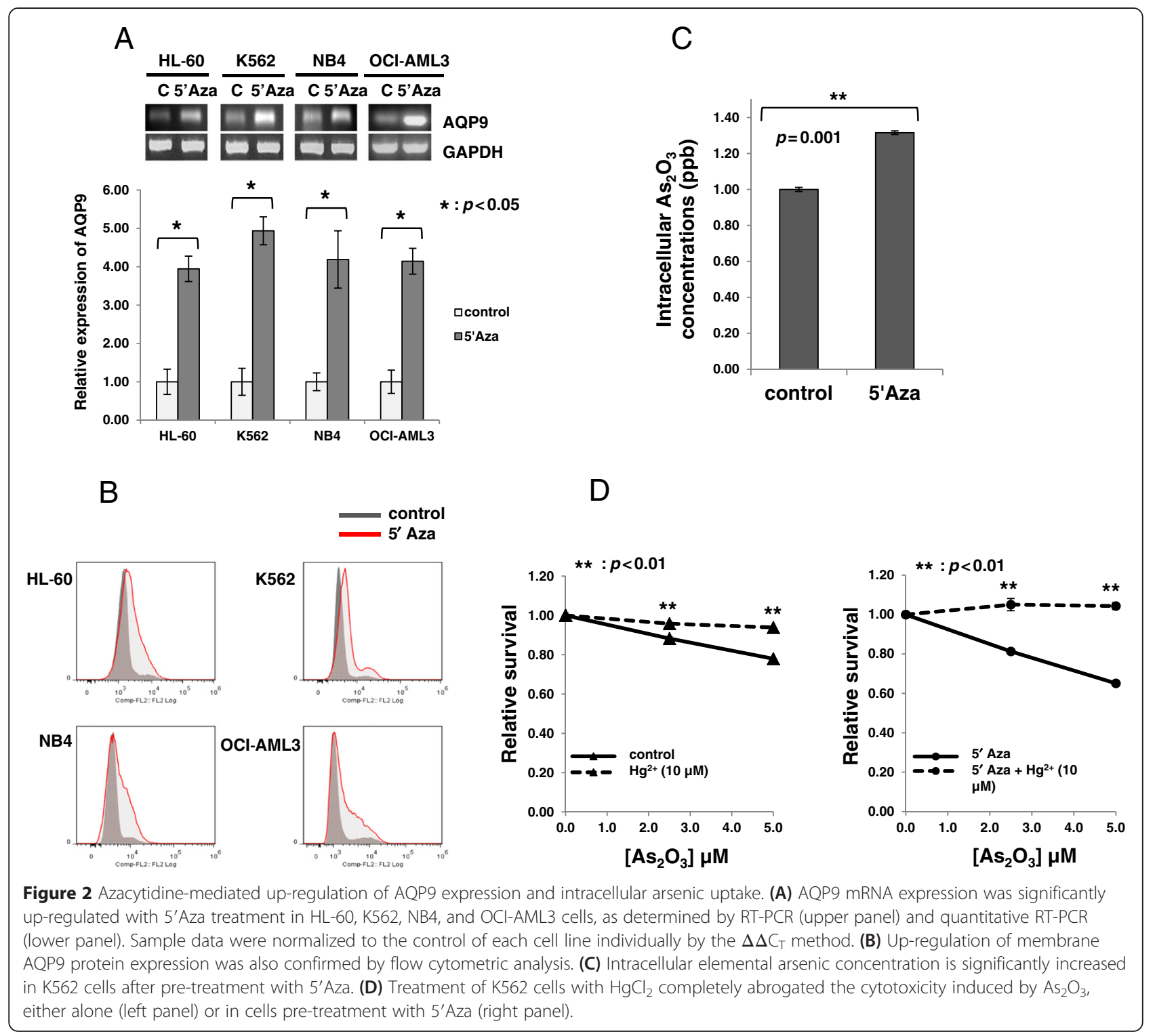

panel), $\mathrm{HgCl}_{2}$ significantly attenuated the cytotoxicity induced by $\mathrm{As}_{2} \mathrm{O}_{3}$. More importantly, $\mathrm{HgCl}_{2}$ treatment also abolished the sensitization to $\mathrm{As}_{2} \mathrm{O}_{3}$ resulting from pretreatment with azacytidine (Figure $2 \mathrm{D}$, right panel). These results illustrated that azacytidine sensitized cells to $\mathrm{As}_{2} \mathrm{O}_{3}$ by increasing AQP9 expression, leading to increased arsenic entry and therefore enhanced cytotoxicity on subsequent exposure to $\mathrm{As}_{2} \mathrm{O}_{3}$.

\section{Transcription factor HNF1A was up-regulated by azacytidine treatment}

A thorough analysis of the DNA sequence of the AQP9 promoter did not show any $\mathrm{CpG}$ islands, implying that up-regulation of AQP9 with azacytidine is not due to $A Q P 9$ promoter demethylation. Examination of the $A Q P 9$

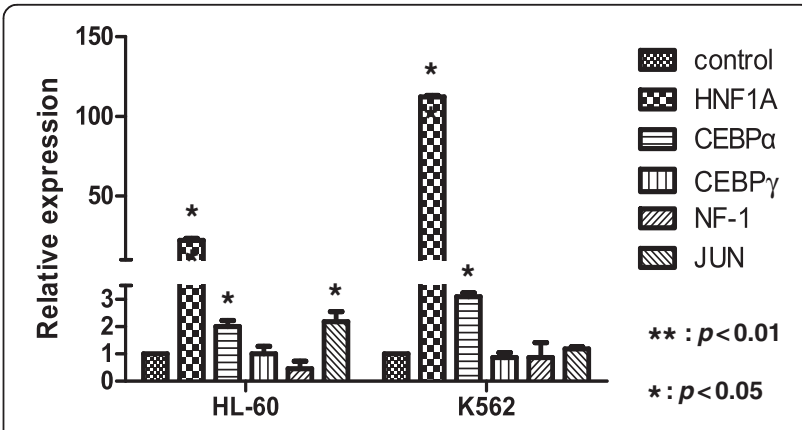

Figure $\mathbf{3}$ Quantitative RT-PCR analysis of the expression of potential transcription factors for the AQP9 gene after $5^{\prime}$ Aza treatment in HL-60 and $\mathrm{K} 562$ cells. The expressions of five transcription factors, including HNF1A, CEBPa, CEBPY, NF-1, and JUN, with or without 5'Aza treatment in $\mathrm{HL}-60$ and $\mathrm{K} 562$ cells, were determined by quantitative RT-PCR. Sample data were normalized to the control gene GAPDH for each cell line individually. 


\section{A}

HNF1A RNA expression:

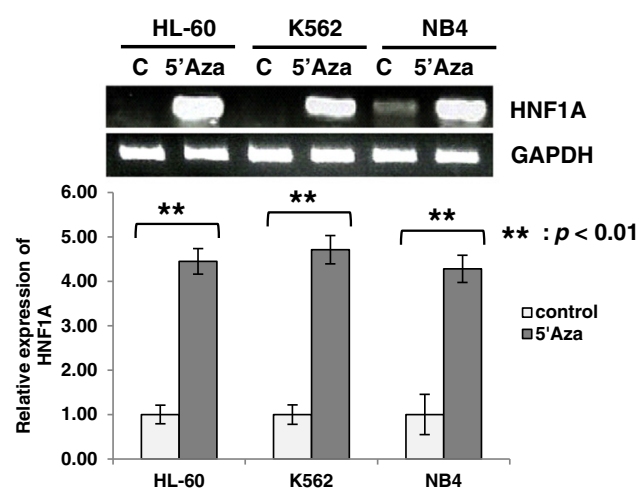

HNF1A protein expression:
B

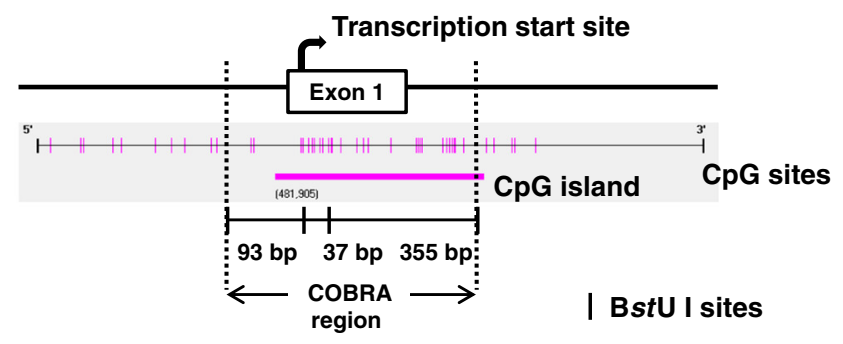

C

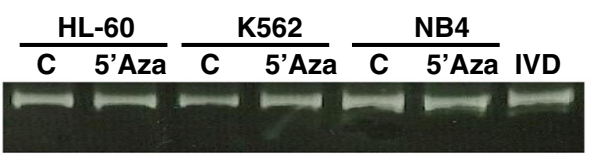

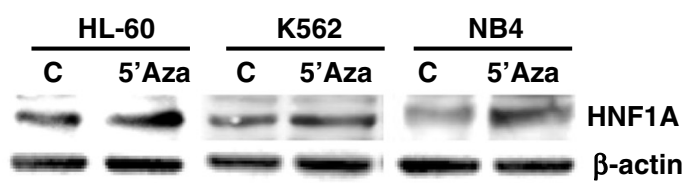

D

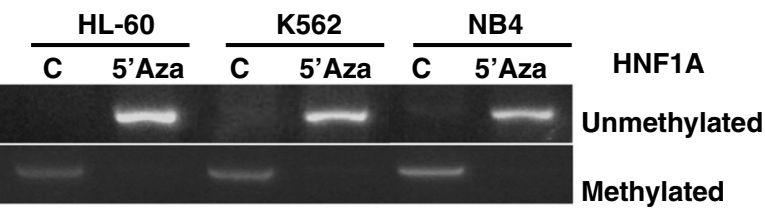

E

\section{K562}

C siHNF1A sicontrol C siHNF1A sicontrol

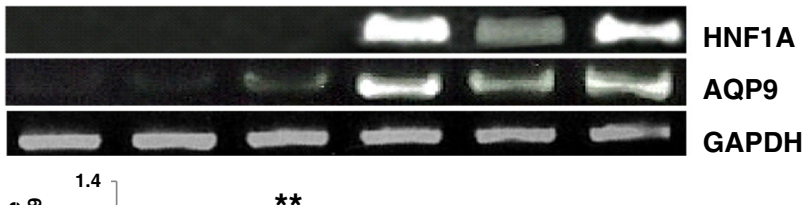

F

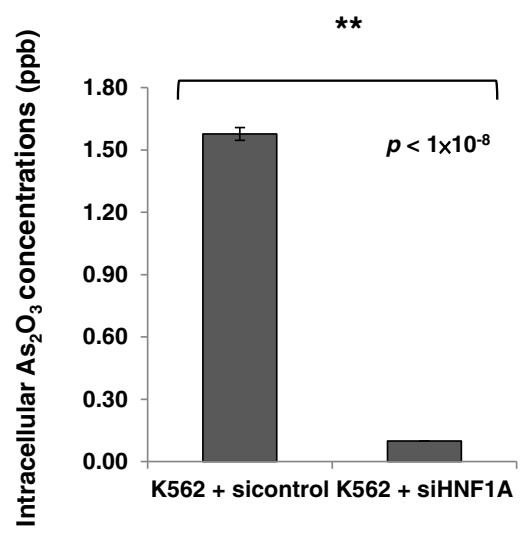

$\leftarrow$ Unmethylated

E\} Methylated

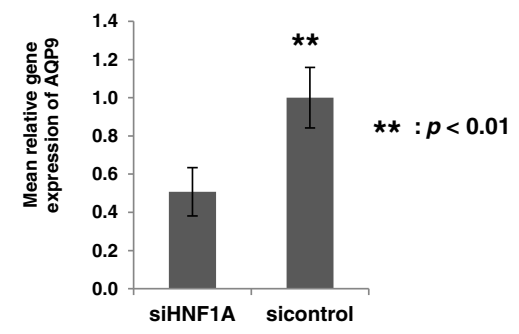

Figure 4 (See legend on next page.) 
(See figure on previous page.)

Figure 4 Transcription factor HNF1A was involved in azacytidine-induced up-regulation of AQP9. (A). HNF1A mRNA and protein expressions were markedly up-regulated after treatment of $5^{\prime}$ Aza as examined by semi-quantitative and quantitative RT-PCR (upper panel) and western immunoblotting (lower panel). (B) Diagram depicting the regions of the HNF1A promoter analyzed by Methylation-specific PCR (MSP) and Combined Bisulfite Restriction Analysis (COBRA). (C) The methylation status of HNF1A gene promoter was extensively studied and determined using combined bisulfite restriction analysis. 5'Aza treatment resulted in demethylation of the HNF1A gene promoter. (C: control; IVD: universal methylated DNA). (D) Methylation-specific PCR (MSP) was performed using PCR primers specific for methylated or unmethylated HNFIA gene promoter. The results showed that the HNF1A gene promoter was highly methylated, and $5^{\prime}$ Aza treatment led to demethylation of the HNF1A gene promoter. (E) Specific HNF1A siRNA abrogated 5'Aza-induced AQP9 up-regulation as determined by RT-PCR (upper panel) and quantitative RT-PCR (lower panel). (F) In K562 cells treated with 5'Aza, specific HNF1A siRNA almost completely blocked the intracellular entry of $\mathrm{As}_{2} \mathrm{O}_{3}$ as compared with the control siRNA-treated cells. The results showed that HNF1A was the mediator for up-regulation of AQP9 after 5'Aza treatment.

promoter via the online database (UCSC Genome Browser on Human Mar. 2006 (NCBI/hg18) Assembly) and published literature showed putative DNA binding sites for several transcription factors, including hepatic nuclear factor 1A (HNF1A), CCAAT/enhancer-binding protein $\alpha$ $(\mathrm{C} / \mathrm{EBP} \alpha), \mathrm{C} / \mathrm{EBP} \gamma, \mathrm{c}-J \mathrm{UN}$, and NF-kB [13]. Quantitative RT-PCR showed that HNF1A was the most significantly and consistently up-regulated transcription factor after azacytidine treatment (Figure 3).

\section{Promoter methylation of HNF1A impacted on AQP9 expression and hence transmembrane arsenic trafficking}

HL-60 and K562 cells expressed very low levels of HNF1A, whereas NB4 cells had a slightly higher basal HNF1A expression (Figure 4A). Treatment with azacytidine led to a marked increase in HNF1A mRNA and protein expression in all three leukemia lines (Figure 4A). The HNF1A promoter contains a stretch of $\mathrm{CpG}$ islands (Figure $4 \mathrm{~B}$ ). With COBRA, the HNF1A promoter was found to be highly methylated in all three AML cell lines, and treatment with azacytidine led to demethylation of the HNF1A promoter (Figure $4 \mathrm{C}$ ). The COBRA findings were replicated in MSP analysis (Figure 4D). To show that azacytidine treatment leading to promoter demethylation and re-expression of HNF1A was biologically relevant, siRNA was used to knock-down HNF1A. As shown in Figure 4E, K562 cells treated with azacytidine showed considerable up-regulation of HNF1A and hence AQP9, which was significantly suppressed with HNF1A siRNA. This resulted in an almost complete blockade of arsenic entry into K562 cells (Figure 4F).

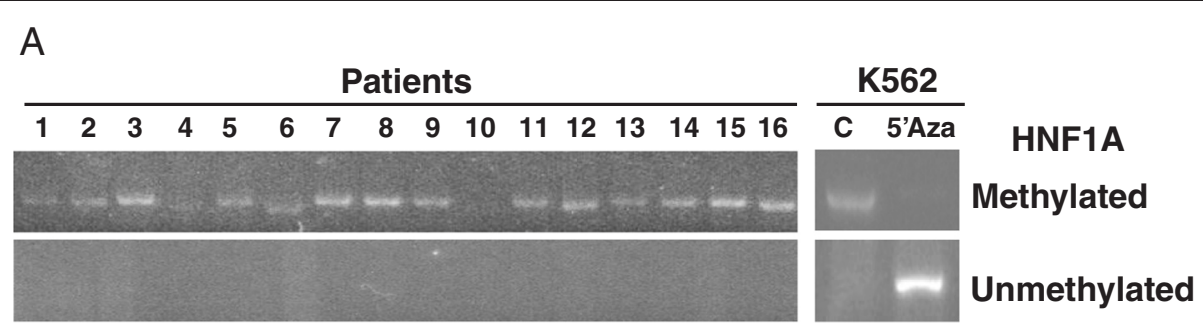

B

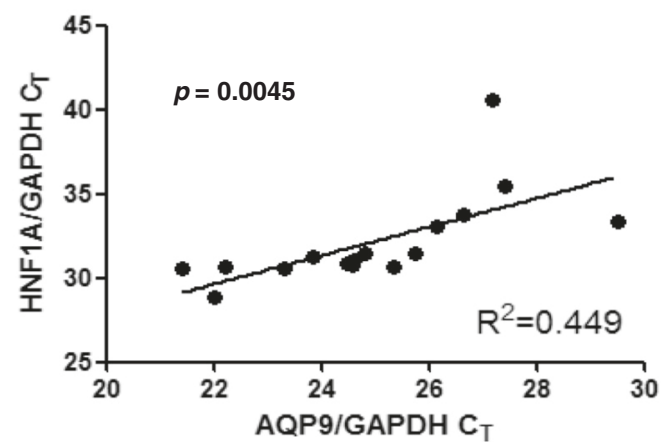

Figure 5 Methylation status of HNF1A promoter and correlation between the expressions of AQP9 and HNF1A in primary AML samples. (A) MSP showing highly methylated HNF1A promoter in 16 human AML samples. (B) Quantification of AQP9 and HNF1A expressions in 16 human AML samples. Result was analyzed using Pearson test. AQP9 level was found to correlate positively with HNF1A level $(p=0.0045)$. 
HNF1A methylation and AQP9 expression in primary AML cells

In an archival panel of 16 non-APL AML cells, MSP showed that HNF1A promoter was highly methylated (Figure 5A). On quantitative RT-PCR, expressions of HNF1A and AQP9 were positively correlated, confirming that HFN1A was an important transcription activator of the $A Q P 9$ gene in AML (Figure $5 \mathrm{~B}$ ).

\section{Azacytidine increased AQP9 level and enhanced} $\mathrm{As}_{2} \mathrm{O}_{3}$-mediated cytotoxicity in primary human $\mathrm{AML}$ cells Circulating AML blasts from seven patients with nonAPL AML were examined. Treatment with azacytidine led to a significant increase in HNF1A and AQP9 expression (Figure 6A). Furthermore, pre-treatment with azacytidine significantly sensitized AML cells to subsequent $\mathrm{As}_{2} \mathrm{O}_{3}$ treatment in all cases (Figure 6B).

Azacytidine pre-treatment and subsequent $\mathrm{As}_{2} \mathrm{O}_{3}$ treatment did not lead to enhanced cytotoxicity in human liver cell line One of the major toxicities of $\mathrm{As}_{2} \mathrm{O}_{3}$ treatment is liver damage, so it is important to determine if azacytidine treatment might exacerbate hepatotoxicity. In the primary liver cell line MIHA [22], basal AQP9 expression was much higher than that of the AML cell lines (Figure 7A). Treatment with azacytidine did not significantly increase AQP9 expression (Figure 7B). MSP showed that the HNF1A promoter was almost totally unmethylated in MIHA cells, and expectedly treatment with azacytidine did not lead to a significant increase in HNF1A expression (Figure 7C). Finally, pre-treatment of MIHA cells with azacytidine did not enhance the cytotoxicity of subsequent $\mathrm{As}_{2} \mathrm{O}_{3}$ treatment (Figure 7D).

\section{Discussion}

With the use of ATRA and chemotherapy, complete remission (CR) rates of over $90 \%$ can be achieved in newly diagnosed APL. In relapsed APL, $\mathrm{As}_{2} \mathrm{O}_{3}$ has been shown to be a highly effective salvage therapy [3]. Combination therapy with $\mathrm{As}_{2} \mathrm{O}_{3}$ and ATRA as frontline treatment for APL also results a very high CR rate and improved long-term outcomes [4,5]. We have also shown that the use of $\mathrm{As}_{2} \mathrm{O}_{3}$ and ATRA as maintenance therapy is safe and may decrease relapse in APL patients in first CR [6].
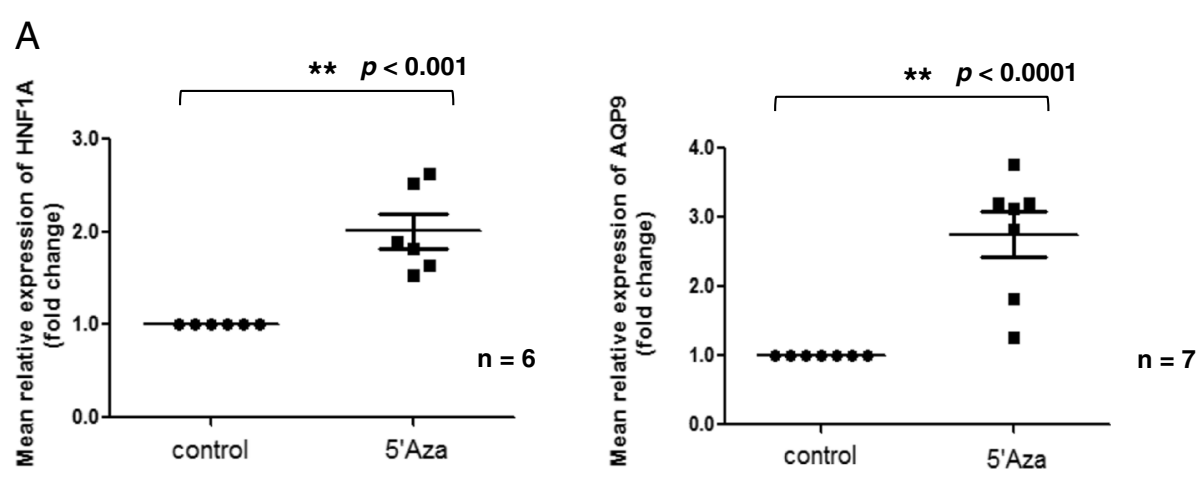

B

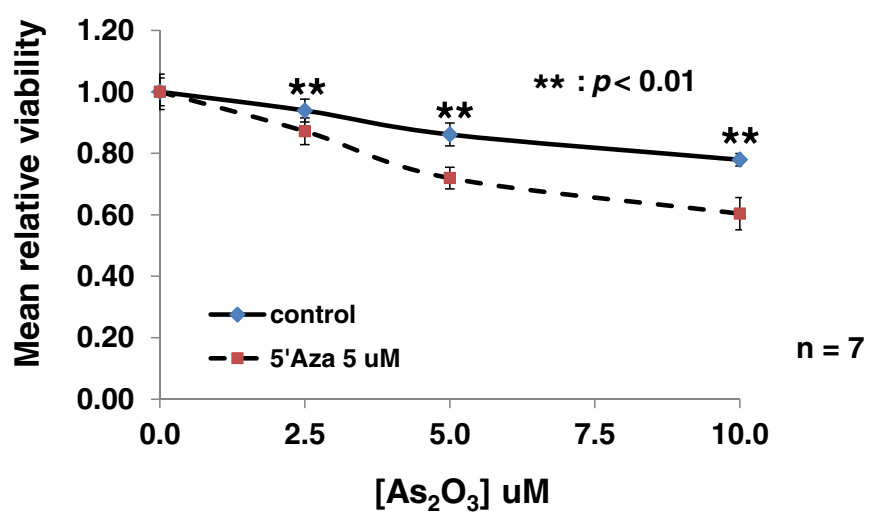

Figure 6 Pre-treatment with azacytidine sensitized primary AML cells to subsequent treatment with $\mathrm{As}_{2} \mathrm{O}_{3}$. (A) Treatment with $5^{\prime}$ Aza resulted in

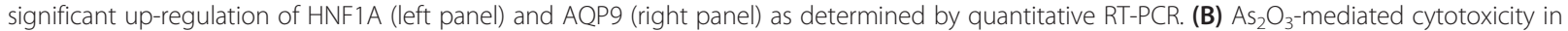
primary AML cells with or without 5'Aza pre-treatment as determined by MTT analysis. Sample data were normalized to the controls of each patient individually. Results represented triplicates of seven samples of primary AML cells. 


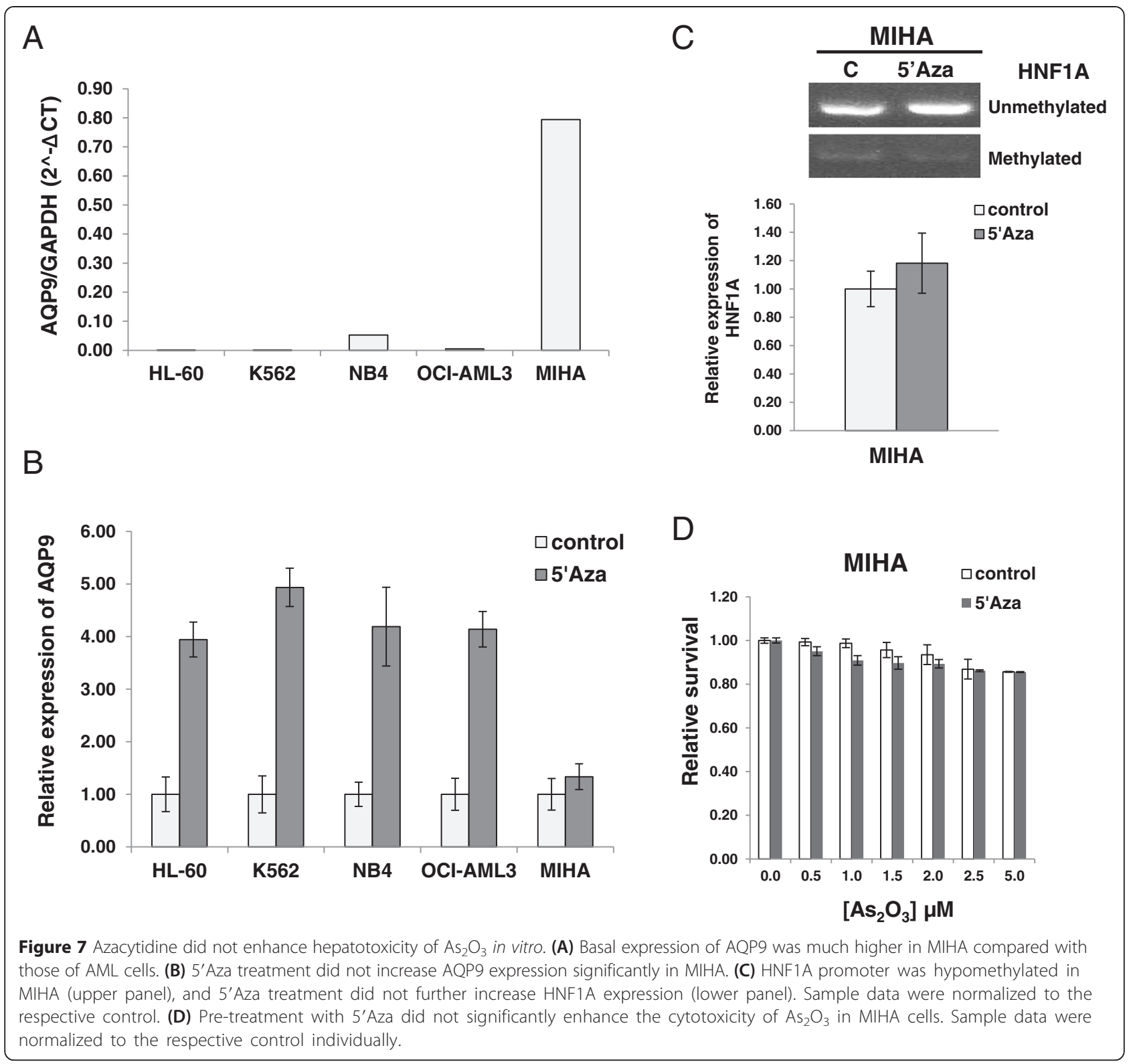

Our previous study showed that one of the mechanisms underlying the synergistic interaction between $\mathrm{As}_{2} \mathrm{O}_{3}$ and ATRA might be ATRA-mediated up-regulation of AQP9, resulting in increased cellular uptake and hence intracellular concentrations of arsenic [14].

In this study, we tested the hypothesis that AQP9 might be involved in the observed synergistic interaction of azacytidine with $\mathrm{As}_{2} \mathrm{O}_{3}$. Because we wanted to minimize the cytotoxic action of azacytidine as a confounding factor in our experiments, azacytidine was used only as a pretreatment and removed from the culture system during subsequent $\mathrm{As}_{2} \mathrm{O}_{3}$ treatment. In this way, we showed that azacytidine pre-treatment sensitized cells to $\mathrm{As}_{2} \mathrm{O}_{3}$ induced cytotoxicity.
Our data clearly showed that azacytidine up-regulated AQP9 through demethylation of the promoter and therefore increased transcription of HNF1A, itself a transcription activator of $A Q P 9$. The increase in AQP9 expression at the transcription and protein levels led to increase arsenic uptake and intracellular concentrations, thereby enhancing $\mathrm{As}_{2} \mathrm{O}_{3}$-induced cytotoxicity. Blockade of AQP9 by $\mathrm{HgCl}_{2}$ and siRNA knock-down of $H N F 1 A$ both suppressed azacytidine-induced $\mathrm{As}_{2} \mathrm{O}_{3}$ sensitization. Because azacytidine was removed after pre-treatment, its intrinsic cytotoxicity did not contribute to the subsequent cytotoxicity observed with $\mathrm{As}_{2} \mathrm{O}_{3}$ treatment. However, in actual clinical practice, if azacytidine were to be combined with $\mathrm{As}_{2} \mathrm{O}_{3}$ in treating patients, the inherent cytotoxicity of 
azacytidine might further enhance cell-kill and hence the clinical efficacy of this combination.

One concern of combined azacytidine $/ \mathrm{As}_{2} \mathrm{O}_{3}$ treatment would be potentiation of arsenic toxicity in other organs and tissues where AQP9 is also up-regulated. The liver is a key organ that is affected by $\mathrm{As}_{2} \mathrm{O}_{3}$ treatment, particularly when $\mathrm{As}_{2} \mathrm{O}_{3}$ is used in the oral formulation due to a first-pass effect. Reassuringly, our preliminary data in MIHA showed that liver cells already expressed a high level of AQP9, which was not further increased by azacytidine treatment. Interestingly, it had been shown that $\mathrm{As}_{2} \mathrm{O}_{3}$-related toxicities, especially in the heart and liver, were more pronounced in AQP9-null mice when compared with wild-type mice, as a result of reduced $\mathrm{As}_{2} \mathrm{O}_{3}$ clearance [25]. Finally, in a phase I clinical trial examining $\mathrm{As}_{2} \mathrm{O}_{3}$ in combination with another demethylating drug decitabine in AML, no excessive adverse effects were reported [21]. Therefore, concomitant azacytidine and $\mathrm{As}_{2} \mathrm{O}_{3}$ treatment might not lead to increased toxicity in other organs.

The transcription regulation of $A Q P 9$ has not been thoroughly investigated, and other pharmacological agents may also activate $A Q P 9$ gene through various mechanisms to enhance the anti-tumor effects of $\mathrm{As}_{2} \mathrm{O}_{3}[14,15]$. Previous investigations had shown that indirubin and tanshinone IIA up-regulated $A Q P 9$ expression and augmented the anti-leukemia effect of $\mathrm{As}_{2} \mathrm{O}_{3}$ as present in the Realgar-Indigo naturalis formula [26]. As AQP9 transmembrane protein can be detected and quantified by fluorochrome-conjugated antibody and flow cytometric analysis, a high-throughput screening is therefore feasible in the future to identify compounds that may up-regulate $\mathrm{AQP9}$ and potentially enhance the therapeutic effect of $\mathrm{As}_{2} \mathrm{O}_{3}$.

HNF1A is a transcription factor and is highly expressed in liver, pancreas, and kidneys [27]. It plays a critical role in transcriptional activation of differentiated hepatocyte-specific genes critical for liver function such as albumin [28]. Epigenetic regulation is involved in tissue-specific expression of HNF1A, and hypomethylation of the HNF1A gene promoter has been demonstrated in mature hepatocytes and renal tubular cells [29]. In kidneys, HNF1A regulates the expression of several organic anion transporters but its role in aquaporin or aquaglyceroporin expression has not been reported previously [29]. Furthermore, HNF1A level has been shown to be associated with differentiation of hepatocellular carcinoma (HCC) [28]. Given that AQP9 expression may be associated with differentiation of myeloid cells [14], it remains to be determined if HNF1A is also involved in myeloid differentiation. Finally, chronic exposure of the HCC cell line HepG2 to sub-toxic levels of arsenic leading to arsenic resistance has been shown to be associated with down-regulation of HNF1A expression [30]. This is in agreement with our result, in that decreasing HNF1A level would result in downregulation of $\mathrm{AQP} 9$, which led to decreased arsenic entry into cells, thereby contributing to arsenic resistance.

\section{Conclusions}

In conclusion, we have provided proof-of-principle evidence that a novel strategy of pharmacological up-regulation of AQP9 might be an approach to increase arsenic sensitivity in neoplastic cells. Furthermore, given that azacytidine is a proven treatment for $\mathrm{AML}$, azacytidine, and $\mathrm{As}_{2} \mathrm{O}_{3}$ would be a logical drug combination to be further evaluated for the treatment of AML in future clinical trials.

\section{Additional file}

Additional file 1: Supplementary Information. Supplementary materials and methods.

\section{Competing interests}

The University of Hong Kong holds the patent for the use of oral formulation of arsenic trioxide in USA and Japan. DC, YLK, and ET are employees of the University of Hong Kong. Other authors report no potential conflicts of interest.

\section{Authors' contributions}

DC and KN contributed equally to this work, performed the experiments, and wrote the manuscript. TSYC managed the patients and collected the clinical data. YYC performed the experiments. BF and ST performed the intracellular arsenic trioxide concentration assays. YLK designed the experiments, managed the patients, and wrote the manuscript. ET conceived the project, designed the experiments, managed the patients, and wrote the manuscript. All authors read and approved the manuscript.

\section{Acknowledgements}

The project was supported by a General Research Fund (HKU779813), Research Grant Council, Hong Kong. ET was a recipient of the Outstanding Young Research Award 2009-10, The University of Hong Kong.

\section{Author details}

${ }^{1}$ Division of Haematology, Department of Medicine, Queen Mary Hospital, The University of Hong Kong, Pok Fu Lam, Hong Kong, Hong Kong.

Department of Pathology and Clinical Biochemistry, Queen Mary Hospital, Pok Fu Lam, Hong Kong, Hong Kong. ${ }^{3}$ Asbestos Diseases Research Institute, ADRI Bernie Banton Centre, University of Sydney, Concord Hospital, Sydney, Australia.

Received: 16 January 2015 Accepted: 27 April 2015 Published online: 08 May 2015

\section{References}

1. Tallman MS, Altman JK. How I treat acute promyelocytic leukemia. Blood. 2009;114:5126-35.

2. Sanz MA, Lo-Coco F. Modern approaches to treating acute promyelocytic leukemia. J Clin Oncol. 2011;29:495-503.

3. Soignet SL, Frankel SR, Douer D, Tallman MS, Kantarjian H, Calleja E, et al. United States multicenter study of arsenic trioxide in relapsed acute promyelocytic leukemia. J Clin Oncol. 2001;19:3852-60.

4. Shen ZX, Shi ZZ, Fang J, Gu BW, Li JM, Zhu YM, et al. All-trans retinoic acid/As2O3 combination yields a high quality remission and survival in newly diagnosed acute promyelocytic leukemia. Proc Natl Acad Sci U S A. 2004;101:5328-35.

5. Lo-Coco F, Avvisati G, Vignetti M, Thiede C, Orlando SM, lacobelli S, et al. Retinoic acid and arsenic trioxide for acute promyelocytic leukemia. N Engl J Med. 2013;369:111-21. 
6. Au WY, Kumana CR, Lee HK, Lin SY, Liu H, Yeung DY, et al. Oral arsenic trioxide-based maintenance regimens for first complete remission of acute promyelocytic leukemia: a 10-year follow-up study. Blood. 2011;118:6535-43.

7. Zhang XW, Yan XJ, Zhou ZR, Yang FF, Wu ZY, Sun HB, et al. Arsenic trioxide controls the fate of the PML-RARalpha oncoprotein by directly binding PML. Science. 2010;328:240-3.

8. Tatham MH, Geoffroy MC, Shen L, Plechanovova A, Hattersley N, Jaffray EG, et al. RNF4 is a poly-SUMO-specific E3 ubiquitin ligase required for arsenic-induced PML degradation. Nat Cell Biol. 2008;10:538-46.

9. Jeanne M, Lallemand-Breitenbach V, Ferhi O, Koken M, Le Bras M, Duffort S, et al. PML/RARA oxidation and arsenic binding initiate the antileukemia response of As2O3. Cancer Cell. 2010;18:88-98.

10. Chen YC, Lin-Shiau SY, Lin JK. Involvement of reactive oxygen species and caspase 3 activation in arsenite-induced apoptosis. J Cell Physiol. 1998;177:324-33.

11. Larochette N, Decaudin D, Jacotot E, Brenner C, Marzo I, Susin SA, et al. Arsenite induces apoptosis via a direct effect on the mitochondrial permeability transition pore. Exp Cell Res. 1999;249:413-21.

12. Li H, Wang $Y, X u$ W, Dong $L$, Guo $Y, B i ~ K$, et al. Arsenic trioxide inhibits DNA methyltransferase and restores TMS1 gene expression in K562 cells. Acta Haematol. 2015;133:18-25.

13. Tsukaguchi H, Weremowicz S, Morton CC, Hediger MA. Functional and molecular characterization of the human neutral solute channel aquaporin-9. Am J Physiol. 1999;277:F685-96.

14. Leung J, Pang A, Yuen WH, Kwong YL, Tse EW. Relationship of expression of aquaglyceroporin 9 with arsenic uptake and sensitivity in leukemia cells. Blood. 2007;109:740-6.

15. Bhattacharjee H, Carbrey J, Rosen BP, Mukhopadhyay R. Drug uptake and pharmacological modulation of drug sensitivity in leukemia by AQP9. Biochem Biophys Res Commun. 2004;322:836-41.

16. Lubbert M, Suciu S, Baila L, Ruter BH, Platzbecker U, Giagounidis A, et al. Low-dose decitabine versus best supportive care in elderly patients with intermediate- or high-risk myelodysplastic syndrome (MDS) ineligible for intensive chemotherapy: final results of the randomized phase III study of the European Organisation for Research and Treatment of Cancer Leukemia Group and the German MDS Study Group. J Clin Oncol. 2011;29:1987-96.

17. Cashen AF, Schiller GJ, O'Donnell MR, DiPersio JF. Multicenter, phase II study of decitabine for the first-line treatment of older patients with acute myeloid leukemia. J Clin Oncol. 2010;28:556-61.

18. Fenaux P, Mufti GJ, Hellstrom-Lindberg E, Santini V, Gattermann N, Germing $U$, et al. Azacitidine prolongs overall survival compared with conventional care regimens in elderly patients with low bone marrow blast count acute myeloid leukemia. J Clin Oncol. 2010;28:562-9.

19. Fenaux P, Mufti GJ, Hellstrom-Lindberg E, Santini V, Finelli C, Giagounidis A, et al. Efficacy of azacitidine compared with that of conventional care regimens in the treatment of higher-risk myelodysplastic syndromes: a randomised, open-label, phase III study. Lancet Oncol. 2009;10:223-32.

20. Peng CY, Jiang J, Zheng HT, Liu XS. Growth-inhibiting effects of arsenic trioxide plus epigenetic therapeutic agents on leukemia cell lines. Leuk Lymphoma. 2010;51:297-303.

21. Welch JS, Klco JM, Gao F, Procknow E, Uy GL, Stockerl-Goldstein KE, et al. Combination decitabine, arsenic trioxide, and ascorbic acid for the treatment of myelodysplastic syndrome and acute myeloid leukemia: a phase I study. Am J Hematol. 2011;86:796-800.

22. Pang RW, Lee TK, Man K, Poon RT, Fan ST, Kwong YL, et al. PIN1 expression contributes to hepatic carcinogenesis. J Pathol. 2006;210:19-25.

23. Au WY, Cheung GT, Yuen TW, Kumana CR, Kwong YL. Successful treatment of relapsed acute promyelocytic leukemia in a patient receiving continuous ambulatory peritoneal dialysis with oral arsenic trioxide. Arch Intern Med. 2005;165:1067-8

24. Ishibashi K, Kuwahara M, Gu Y, Tanaka Y, Marumo F, Sasaki S. Cloning and functional expression of a new aquaporin (AQP9) abundantly expressed in the peripheral leukocytes permeable to water and urea, but not to glycerol. Biochem Biophys Res Commun. 1998;244:268-74.

25. Carbrey JM, Song L, Zhou Y, Yoshinaga M, Rojek A, Wang Y, et al. Reduced arsenic clearance and increased toxicity in aquaglyceroporin-9-null mice. Proc Natl Acad Sci U S A. 2009;106:15956-60.

26. Wang L, Zhou GB, Liu P, Song JH, Liang Y, Yan XJ, et al. Dissection of mechanisms of Chinese medicinal formula Realgar-Indigo naturalis as an effective treatment for promyelocytic leukemia. Proc Natl Acad Sci U S A 2008;105:4826-31.
27. Mendel DB, Crabtree GR. HNF-1, a member of a novel class of dimerizing homeodomain proteins. J Biol Chem. 1991;266:677-80.

28. Costa RH, Kalinichenko W, Holterman AX, Wang X. Transcription factors in liver development, differentiation, and regeneration. Hepatology. 2003;38:1331-47

29. Kikuchi R, Yagi S, Kusuhara H, Imai S, Sugiyama Y, Shiota K. Genome-wide analysis of epigenetic signatures for kidney-specific transporters. Kidney Int. 2010;78:569-77.

30. Pastoret A, Marcos R, Sampayo-Reyes A, Saucedo-Cardenas O, Lozano-Garza $\mathrm{GH}$, Hernandez A. Inhibition of hepatocyte nuclear factor 1 and 4 alpha (HNF1alpha and HNF4alpha) as a mechanism of arsenic carcinogenesis. Arch Toxicol. 2013;87:1001-12.

\section{Submit your next manuscript to BioMed Central and take full advantage of:}

- Convenient online submission

- Thorough peer review

- No space constraints or color figure charges

- Immediate publication on acceptance

- Inclusion in PubMed, CAS, Scopus and Google Scholar

- Research which is freely available for redistribution 